\title{
FACTORS AFFECTING UTILIZATION OF ANTENATAL CARE SERVICES AMONG WOMEN VISITING FOR INSTITUTIONAL DELIVERY IN TERTIARY HOSPITAL, BHAIRAHAWA, NEPAL: A CROSS SECTIONAL STUDY
}

Rubina Shrestha, ${ }^{1}$ Chet Kant Bhusal, ${ }^{1}$ Pradip Chhettri, ${ }^{1}$ Saneep Shrestha, ${ }^{1}$ Jyoti Priyanka

\section{ABSTRACT}

\section{INTRODUCTION}

Antenatal Care (ANC) services utilization during pregnancy plays an important role in prevention and management of pregnancy related complication thus improving the maternal and child health. Hence this study aimed to identify the factors influencing utilization of ANC service among women visiting for institutional delivery in tertiary hospital of Bhairahawa, Nepal.

\section{MATERIAL AND METHODS}

Hospital based cross-sectional study was carried among 396 women admitted in the postnatal ward of Universal College of Medical Sciences and Teaching Hospital, Bhairahawa, Nepal form September 2019 to December 2019 following ethical clearance and verbal consent from participants. Variables with significant association $(p<0.05)$ in bivariate analysis were entered into multivariate logistic regression to find the factors affecting utilization of antenatal care services.

\section{RESULTS}

This study revealed that $18.43 \%$ of respondents did not receive any ANC services. Among those who were not receiving ANC service, $86.3 \%$ never felt the need for ANC services throughout the period of pregnancy. ANC service utilization was found to be associated with religion $(\mathrm{AOR}=3.15,95 \% \mathrm{CI}: 1.40-7.08)$ and husband education $(\mathrm{AOR}=5.09,95 \% \mathrm{CI}$ : 1.63 15.92).

\section{CONCLUSION}

In spite of being an essential component for the care of pregnant women, ANC services was not utilized by all of them as many of them did not felt the need of this service. Thus, it is recommended to increase awareness regarding the available services and its importance by local stakeholders to prevent further morbidity and mortality.

\section{KEYWORDS}

Antenatal care, Institutional delivery, Utilization.

1. Department of Community Medicine, Universal College of Medical Sciences, Bhairahawa, Nepal

DOI: https://doi.org/10.3126/jucms.v9i02.41992

For Correspondence

Dr. Rubina Shrestha

Department of Community Medicine Universal College of Medical Sciences,

Bhairahawa, Nepal

Email: rubinashrestha82@gmail.com 


\section{INTRODUCTION}

Antenatal care (ANC) is an essential element of safe motherhood program which aims to achieve healthy mother and healthy baby at the end of the pregnancy. Prevention of complications related to pregnancy depends on continuum of quality care being provided before and during pregnancy, childbirth and the postnatal period.' The risk of maternal mortality due to different expected pregnancy complications is higher in different parts of the world due to higher fertility rates, poorer nutritional status and inaccessibility to ANC services. ${ }^{23}$ Nepal is one of the country in South Asia where maternal mortality ratio is still high with 239 deaths per 100,000 live births, one of the reason being little and inequitable utilization of maternal health services. ${ }^{1,4,5}$

World Health Organization (WHO) recommends a minimum of four (ANC) visits for all women with normal pregnancies. ${ }^{6}$ Ministry of Health and Population (MoHP) Nepal, has an important role in extension of maternal and child health services, providing ANC services at community level. ${ }^{7} \mathrm{MoHP}$ launched maternity incentives scheme in 2005 with provision of a fixed amount of money for transportation based on ecological region of the country. Further, on completing four ANC on 4, 6, 8 and 9 months incentive was introduced in 2009 to promote antenatal services along with institutional delivery. ${ }^{8}$ Despite all ongoing efforts to increase ANC service utilization, wide disparities prevail among women in rural and urban parts of the country.

Though ANC service seeking behavior in Nepal has improved since 1990s and women pursuing health services are increasing, still there are a relatively high percentage who does not pursue even a onetime ANC service.' Further, the percentage of pregnant women who pursue four or more ANC care from a skilled service provider is low. Many women still do not follow the recommendation of four visits or more and do not seek care required during pregnancy, which affects the utilization of ANC services. According to national data $84 \%$ of women had their antenatal care from a skilled provider at least once and $69 \%$ had four or more than four visits. ${ }^{1}$ This decrease in coverage of four ANC visits signifies a concern to understand the factors accessing the recommended ANC visits. Thus this study aimed to identify different factors influencing utilization of ANC services among women visiting for institutional delivery.

\section{MATERIAL AND METHODS}

\section{Study design, place and duration of study}

Hospital based cross-sectional study was conducted among women admitted in the postnatal ward of Universal College of
Medical Sciences, Bhairahawa from September 2019 to December 2019 (4 months).

\section{Ethical consideration}

Ethical approval was taken from Institutional Review committee of Universal College of Medical Sciences (UCMS/IRC/066/19). All the women included in the study were informed about the purpose of the study and participated with their verbal consent.

\section{Inclusion criteria and exclusion criteria}

Those women who were admitted in the postnatal ward of UCMS and willing to participate were included in the study. Those women who were having complications following delivery were excluded from the study.

\section{Sample size and sampling technique}

Purposive sampling method was used to select the respondents admitted in the postnatal ward.

Sample size was calculated by using formula $\mathrm{n}=\mathrm{z}^{2} \mathrm{pq} / \mathrm{d}^{2}$ where $\mathrm{Z}$ is level of significance at $5 \%=1.96, p=0.57$ (prevalence of institutional delivery $57 \%)^{1}, \mathrm{q}=1-\mathrm{p}=0.43, \mathrm{~d}=$ allowable error $5 \%$.

$$
\text { Sample size }(n)=\frac{Z^{2} p q}{d^{2}}=\frac{(1.96 \times 1.96)(0.57)}{(0.05)^{2}}(\underline{(0.43)}=376.63
$$

Considering a non-response rate of 5\%, the final sample size of the study was 395.83 . Hence, a total of 396 respondents were included in the study.

Face to face interview was done by principal investigator using semi-structured pre-tested questionnaire. Questions were asked in their language so that the respondent understood the questions properly. The questionnaire included two sets of variables categorized as dependent and independent. ANC service utilization in the form of ANC visits was taken as the dependent variable. Those who completed at least four or more than four ANC visits were considered to have good ANC service utilization. Independent variables were categorized in three sections including the questions regarding background related characteristics, knowledge and practice regarding ANC services.

\section{Statistical analysis and software used}

Data editing, coding and cleaning was done manually on regular basis. Collected data were entered into SPSS software version 20 for analysis. Descriptive analysis was performed to calculate frequency, percentage, mean and standard deviation. Bivariate logistic regression analysis was conducted for crude odds ratio and $\mathrm{p}$ value was considered from chi-square test. Those variables which were significant having $p<0.05$ were 
taken into consideration for the processing of multivariate logistic regression model to identify factors affecting utilization of ANC services.

\section{RESULTS}

The study showed that the average age of the respondents was $24.96 \pm 4.30$ years, with a majority of $299(75.5 \%)$ belonging to $20-30$-year age group. Most of the respondents $79 \%$ were Hindus, $33.6 \%$ were illiterate, $96.4 \%$ of them were housewives, $74.5 \%$ were from joint family, $50.5 \%$ were pregnant for the first time and $77.3 \%$ had $1-2$ living child Regarding their husbands, $30.8 \%$ were having SLC and above education and most of them $84.09 \%$ were involved in occupation other than agriculture (Table 1).

\section{Table 1. Background related characteristics}

\begin{tabular}{|c|c|c|}
\hline Characteristics & Frequency $(\mathrm{n}=396)$ & Percentage (\%) \\
\hline \multicolumn{3}{|l|}{ Age } \\
\hline$<20$ & 62 & 15.7 \\
\hline $20-30$ & 299 & 75.5 \\
\hline $31-40$ & 35 & 8.8 \\
\hline \multicolumn{3}{|l|}{ Religion } \\
\hline Hindu & 313 & 79.0 \\
\hline Muslim & 83 & 21.0 \\
\hline \multicolumn{3}{|l|}{ Ethnicity } \\
\hline Dalit & 76 & 19.2 \\
\hline Janjati & 74 & 18.7 \\
\hline Madhesi & 108 & 27.3 \\
\hline Muslim & 83 & 20.9 \\
\hline Brahmin/Chhetri & 55 & 13.9 \\
\hline \multicolumn{3}{|l|}{ Respondent Education } \\
\hline Illiterate & 133 & 33.6 \\
\hline Primary school & 63 & 15.9 \\
\hline Secondary school & 99 & 25.0 \\
\hline SLC and above & 101 & 25.5 \\
\hline \multicolumn{3}{|l|}{ Husband education } \\
\hline Illiterate & 84 & 21.2 \\
\hline Primary school & 69 & 17.4 \\
\hline Secondary school & 121 & 30.6 \\
\hline SLC and above & 122 & 30.8 \\
\hline \multicolumn{3}{|l|}{ Occupation } \\
\hline House wife & 382 & 96.4 \\
\hline Other than house wife & 14 & 3.6 \\
\hline \multicolumn{3}{|l|}{ Husband occupation } \\
\hline Agriculture & 63 & 15.9 \\
\hline Other than agriculture & 333 & 84.09 \\
\hline \multicolumn{3}{|l|}{ Type of Family } \\
\hline Nuclear & 101 & 25.5 \\
\hline Joint & 295 & 74.5 \\
\hline \multicolumn{3}{|c|}{ Earning status of respondent } \\
\hline Yes & 14 & 3.6 \\
\hline No & 382 & 96.4 \\
\hline \multicolumn{3}{|l|}{ Number of pregnancy } \\
\hline 1 & 200 & 50.5 \\
\hline 2 & 97 & 24.5 \\
\hline$\geq 3$ & 99 & 25.0 \\
\hline \multicolumn{3}{|c|}{ Number of living children } \\
\hline None & 18 & 4.5 \\
\hline $1-2$ & 306 & 77.3 \\
\hline$\geq 3$ & 72 & 18.2 \\
\hline \multicolumn{3}{|l|}{ History of Abortion } \\
\hline Yes & 14 & 3.6 \\
\hline No & 382 & 96.4 \\
\hline \multicolumn{3}{|c|}{ Belief in traditional healer } \\
\hline Yes & 121 & 30.6 \\
\hline No & 275 & 69.4 \\
\hline
\end{tabular}

\section{Knowledge and practice regarding Antenatal Care}

Among all the respondents majority 360 (90.9\%) had heard about ANC visits. Out of those who had heard about ANC visits, 46.2\% were aware about four ANC visits and the primary source of information was from mass media (35.1\%). In total two hundred thirteen $(53.8 \%)$ of the respondents were aware of the incentives being provided by the Government which included ANC incentives, free delivery service and transportation incentives.

There were $18.4 \%$ of respondents who never attended any ANC visits, out of which $86.3 \%$ never felt the need to visit. Those who had their ANC visits, 129 (40\%) of them received the service more than four times and 93 (28.7\%) received exactly for four times concluding good service utilization by $68.7 \%$ of them (Table 2 ).

Table 2. Knowledge and practice regarding Antenatal care

\begin{tabular}{|c|c|c|}
\hline Characteristics & Frequency $(n=396)$ & Percentage \\
\hline \multicolumn{3}{|l|}{ Knowledge about ANC } \\
\hline Heard about ANC & 360 & 90.9 \\
\hline \multicolumn{3}{|l|}{$\begin{array}{l}\text { Known about recommended ANC visits } \\
(\mathrm{n}=360)\end{array}$} \\
\hline $\begin{array}{l}4 \text { visit } \\
\text { Other than } 4 \text { visit } \\
\text { Source of information* }\end{array}$ & $\begin{array}{l}183 \\
177\end{array}$ & $\begin{array}{l}46.2 \\
53.8\end{array}$ \\
\hline Health personal & 132 & 33.3 \\
\hline $\begin{array}{l}\text { Friend } \\
\text { Family members }\end{array}$ & $\begin{array}{c}73 \\
114\end{array}$ & $\begin{array}{l}18.4 \\
28.8\end{array}$ \\
\hline Mass media & 139 & 35.1 \\
\hline FCHV & 72 & 18.2 \\
\hline Known about ANC incentives & 213 & 53.8 \\
\hline Known about free deliver service & 213 & 53.8 \\
\hline Known about transportation incentives & 213 & 53.8 \\
\hline \multicolumn{3}{|l|}{ Practice about $\mathrm{ANC}$} \\
\hline Women with ANC visits & 323 & 81.6 \\
\hline Women with no ANC visits & 73 & 18.4 \\
\hline \multicolumn{3}{|l|}{ Number of ANC visited $(n=323)$} \\
\hline Twice & 39 & 12.1 \\
\hline Thrice & 62 & 19.2 \\
\hline Four & 93 & 28.7 \\
\hline$>4$ & 129 & 40.0 \\
\hline \multicolumn{3}{|l|}{ Reason for not attending ANC $(n=73)$} \\
\hline No need felt & 63 & 86.3 \\
\hline Unaware & 3 & 4.1 \\
\hline Family constrains & 7 & 9.6 \\
\hline \multicolumn{3}{|l|}{ Place of ANC visit $(n=323)$} \\
\hline Tertiary Hospital & 49 & 12.4 \\
\hline District Hospital & 74 & 18.7 \\
\hline Peripheral & 200 & 50.5 \\
\hline \multicolumn{3}{|l|}{ ANC service Provider $(n=323)$} \\
\hline Doctor & 112 & 25.8 \\
\hline Other than Doctor & 222 & 56.1 \\
\hline
\end{tabular}

*Multiple response given by the respondents

\section{Factors associated with utilization of ANC services}

Multivariate analysis revealed that the women from Hindu religion were 3.15 times $(\mathrm{AOR}=3.15,95 \% \mathrm{CI}: 1.40-7.08)$ 
more likely to use ANC services than women from Muslim religion. Similarly women whose husband had higher education (SLC and above) were 5 times $(\mathrm{AOR}=5.09,95 \%$ CI: 1.63-15.92) more likely to use ANC services then those whose husbands were illiterate (Table 3).

Table 3. Factors associated with utilization of ANC service using bivariate and multivariate logistic regression

\begin{tabular}{|c|c|c|c|c|c|}
\hline \multirow{2}{*}{ Variables } & \multicolumn{2}{|c|}{ ANC visit } & \multirow[t]{2}{*}{ COR $(95 \%$ C.I $)$} & \multirow[t]{2}{*}{ AOR (95\%C.I) } & \multirow[t]{2}{*}{$p$ value } \\
\hline & $\begin{array}{l}<4 \text { ANC } \\
(\%)\end{array}$ & $\begin{array}{l}\geq 4 \text { ANC } \\
(\%)\end{array}$ & & & \\
\hline \multicolumn{6}{|l|}{ Religion } \\
\hline Muslim & $61(73.5)$ & $22(26.5)$ & 1 & 1 & \\
\hline Hindu & $113(36.1)$ & $200(63.9)$ & $4.91(2.86-8.41)$ & $3.15(1.40-7.08)$ & 0.006 \\
\hline \multicolumn{6}{|c|}{$\begin{array}{l}110(00.1) \\
\end{array}$} \\
\hline$<20$ & $32(51.6)$ & $30(48.4)$ & 1 & - & \\
\hline $20-30$ & $125(41.8)$ & $174(58.2)$ & $1.48(0.86-2.57)$ & & \\
\hline $31-40$ & $17(48.6)$ & $18(51.4)$ & $1.13(0.49-2.59)$ & & \\
\hline \multicolumn{6}{|c|}{ Caste/Ethnicity } \\
\hline Dalit & $84(55.7)$ & $35(44.3)$ & 1 & 1 & \\
\hline Non Dalit & $130(41.0)$ & $187(59.0)$ & $1.81(1.10-2.97)$ & $1.42(0.72-2.82)$ & 0.31 \\
\hline \multicolumn{6}{|c|}{ Respondent Education } \\
\hline Illiterate & $90(67.7)$ & $43(32.3)$ & 1 & 1 & \\
\hline Primary & $37(58.7)$ & $26(41.3)$ & $1.47(0.79-2.73)$ & $1.01(0.40-2.58)$ & 0.836 \\
\hline Secondary & $32(32.3)$ & $67(67.7)$ & $4.38(2.51-7.64)$ & $1.09(0.48-2.44)$ & \\
\hline SLC\& above & $15(14.9)$ & $86(85.1)$ & $12(6.21-23.16)$ & $1.08(0.39-3.03)$ & \\
\hline \multicolumn{6}{|c|}{ Husband Education } \\
\hline Illiterate & $66(78.6)$ & $18(21.4)$ & 1 & 1 & \\
\hline Primary & $44(63.8)$ & $25(36.2)$ & $2.08(1.01-4.26)$ & $1.48(0.54-4.03)$ & 0.016 \\
\hline Secondary & $42(34.7)$ & $79(65.3)$ & $6.89(3.63-13.10)$ & $3.07(1.21-7.82$ & \\
\hline SLC\& above & $22(18.0)$ & $100(82.0)$ & $16.66(8.30-33.43)$ & $5.09(1.63-15.92)$ & \\
\hline $\begin{array}{l}\text { Occupation } \\
\text { House wife }\end{array}$ & $168(44.0)$ & $214(56.0)$ & 1 & & \\
\hline $\begin{array}{l}\text { Other than house } \\
\text { wife }\end{array}$ & $6(42.9)$ & $8(57.1)$ & $1.05(0.36-3.07)$ & - & \\
\hline \multicolumn{6}{|c|}{ Husband Occupation } \\
\hline Agriculture & $28(44.0)$ & $35(55.6)$ & 1 & & \\
\hline $\begin{array}{l}\text { Other than } \\
\text { Agriculture }\end{array}$ & $146(43.8)$ & $187(56.2)$ & $1.02(0.60-1.76)$ & & \\
\hline \multicolumn{6}{|l|}{ Type of family } \\
\hline Nuclear & $56(55.4)$ & $45(44.6)$ & 1 & 1 & \\
\hline Joint & $118(40.0)$ & $177(60.0)$ & $1.8(1.18-2.9)$ & $1.32(0.67-2.61)$ & 0.421 \\
\hline \multicolumn{6}{|l|}{ No of pregnancy } \\
\hline 1 & $73(36.5)$ & $127(63.5)$ & 1 & 1 & \\
\hline 2 & $39(40.2)$ & $58(59.8)$ & $0.85(0.52-1.40)$ & $1.08(0.55-2.11)$ & 0.388 \\
\hline$\geq 3$ & $62(62.6)$ & $37(37.4)$ & $0.34(0.21-0.56)$ & $2.50(0.68-9.25)$ & \\
\hline \multicolumn{6}{|c|}{ No of living children } \\
\hline None & $9(50.0)$ & $9(50.0)$ & 1 & 1 & \\
\hline $1-2$ & $118(38.6)$ & $188(61.4)$ & $1.60(0.61-4.12)$ & $0.98(0.22-4.57)$ & 0.280 \\
\hline $\begin{array}{l}>2 \\
\text { Earning Status }\end{array}$ & $47(65.3)$ & $25(34.7)$ & $0.53(0.18-1.51)$ & $0.33(0.05-2.14)$ & \\
\hline Yes & $6(46.2)$ & $7(53.8)$ & 1 & - & \\
\hline No & $168(43.9)$ & $215(56.1)$ & $1.10(0.36-3.36)$ & & \\
\hline \multicolumn{6}{|c|}{ Place of ANC visit } \\
\hline Tertiary Hospital & $4(8.2)$ & $45(91.8)$ & 1 & 1 & \\
\hline District Hospital & $20(27.0)$ & $54(73.0)$ & $0.24(0.08-0.75)$ & $0.61(0.15-2.46)$ & 0.097 \\
\hline $\begin{array}{l}\text { Peripheral } \\
\text { ANC service }\end{array}$ & $77(38.5)$ & $123(61.5)$ & $0.14(0.05-0.41)$ & $0.31(0.83-1.14)$ & \\
\hline \multicolumn{6}{|l|}{ Provider } \\
\hline Doctor & $15(14.7)$ & $87(85.3)$ & 1 & 1 & \\
\hline $\begin{array}{l}\text { Other than } \\
\text { Doctor }\end{array}$ & $86(38.9)$ & $135(61.1)$ & $0.26(0.14-0.49)$ & $0.49(0.21-1.11)$ & 0.087 \\
\hline
\end{tabular}

\section{DISCUSSION}

In spite of implementation of safe motherhood program in Nepal to promote increase utilization of institutional delivery services including free delivery care, 4 ANC visit incentives and transportation incentive, complete ANC visit is still quite low. This study revealed that $90.9 \%$ of the women participated had heard about the antenatal care services in line to other study done in Nepal which showed that $95.5 \%$ of women had heard about ANC services. ${ }^{10}$ Further, more than four-fifth of the respondents received ANC services and more than twothird had at least four ANC visits which is in line with the national data. ${ }^{1}$ However in contrast to this, another study done in hilly area of Nepal found lower proportion of women received ANC services. ${ }^{11}$ This differences might be due to the rural topography and lack of awareness in the women residing in hilly area of Nepal. The remaining $18.4 \%$ of women in this study did not receive any antenatal care services and this finding is similar to the study done in hilly area of Nepal where $21.1 \%$ did not receive any antenatal care services. ${ }^{11}$ Whereas other study showed that $11.4 \%$ of the respondent had no ANC visits which is less in comparison to this study. ${ }^{10}$ The reason behind this difference in the findings might be because of different characteristics of the respondents, study area, geographical area and the sampling method used.

More than half of the respondents had knowledge on ANC incentives, free delivery and transportation incentives however this finding is in contrast with findings from other studies done for evaluating delivery incentive program and knowledge on incentive program which showed $25 \%$ and $60.6 \%$ of the respondents had knowledge on same. ${ }^{10,12}$ This might be because of difference in the level of awareness received amongst the respondents through a widespread dissemination of information from the Government, health facilities and health workers. Significant association was observed amongst women from Hindu religion and utilization of four or more ANC visits in comparison to women form Muslim religion which is similar to the findings from other studies conducted in Nepal. ${ }^{13,14}$ Further this study revealed that the education of husband also had a similar effect on the receiving of four or more ANC visits with a significant association among those having higher education as compared to those who were illiterate. This is similar to the study done in low-income countries and a population based study done in Nepal. ${ }^{15,16}$ Significant effect of husband's education on antenatal care utilization was also seen in the study done among Nigerian adolescents. ${ }^{17}$

The study found no association between women education and utilization of ANC services. This is in contrast to the previous studies which emphasized the importance of education and awareness among women, especially among 
those who are uneducated. ${ }^{18-20}$ This might be due to the reason that this study was conducted in Tertiary Hospital, and most of the respondent visiting for ANC included educated mothers. Similarly, present study found no association of maternal age and parity with utilization of $\geq 4$ ANC services, which was contrary to the findings of many other studies conducted in Nepal. ${ }^{16,21,22}$ This might be due to different study setting, characteristics and methodology in various studies.

\section{CONCLUSION}

Although majority of women had heard about ANC services, less than half had known about recommended 4 ANC visits. Factors such as religion and husband education were found to be associated with utilization of antenatal care services. Women who did not receive any ANC services mentioned that they never felt the need for. Based on these findings, the availability and quality of antenatal care services needs further strengthening and increase in awareness regarding the services and its benefits among general population.

\section{ACKNOWLEDGEMENTS}

We thank institutional review board of Universal College of Medical Sciences for the ethical approval of the study. We also thank all the participants from the postnatal ward for providing their valuable time and information for the study.

\section{CONFLICT OF INTEREST}

None

\section{REFERENCES}

1. Ministry of Health - MOH/Nepal, New ERA/Nepal, ICF. Nepal Demographic and Health Survey 2016. Kathmandu, Nepal: MOH/Nepal, New ERA, and ICF, 2017.

2. Organization WH. World health statistics 2016: monitoring health for the SDGs sustainable development goals: World Health Organization; 2016

3. Nikiéma B, Beninguisse G, Haggerty JL. Providing information on pregnancy complications during antenatal visits: unmet educational needs in sub-Saharan Africa. Health policy and planning. 2009;24(5):367-76

4. Organization WH, UNICEF. Trends in maternal mortality: 1990-2015: estimates from WHO, UNICEF, UNFPA, World Bank Group and the United Nations Population Division. 2015.

5. Gill K, Pande R, Malhotra A. Women deliver for development. The Lancet. 2007;370(9595):1347-57.

6. Organization WH. Far more pregnant women getting antenatal care. Far more pregnant women getting antenatal care 2004.

7. Paudel D, Shrestha IB, Siebeck M, Rehfuess EA. Neonatal health in Nepal: analysis of absolute and relative inequalities and impact of current efforts to reduce neonatal mortality. BMC Public Health. 2013;13(1):1239.

8. Upreti SR, Baral S, Lamichhane P, Khanal MN, Tiwari S, Tandan M, Elsey H and Lievens T . Rapid Assessment of the Demand Side Financing Schemes: Aama and 4ANC Programmes (The Seventh Rapid Assessment). Ministry of Health and Population; Nepal Health Sector Support Programme and Health Research and Social Development Forum, Kathmandu, Nepal, 2013.

9. Chandhiok N, Dhillon BS, Kambo I, Saxena NC. Determinants of antenatal care utilization in rural areas of India: A crosssectional study from 28 districts (An ICMR task force study). J Obstet Gynecol India. 2006;56(1):47-52.

10. Subedi S, Kaphle HP, Acharya S, Gupta N, Jain V. Maternal incentive scheme in Nepal-status of knowledge and financial benefits received by mothers on ANC incentive and safe delivery incentive program. Indian Journal of Community Health. 2014;26(3):273-7.

11. Sanjel S, Ghimire R, Pun K. Antenatal care practices in Tamang community of hilly area in central Nepal. Kathmandu University Medical Journal. 2011;9(2):57-61.

12. Powel-Jackson T, Neupane B, Tiwari S, Morrison J, Costello A. Evaluation of safe delivery incentive programme: Report of the Evaluation. Kathmandu: SSMP, Nepal. 2008.

13. Acharya SK. Demographic and Socio-economic Factors Affecting antenatal care services utilization in Nepal. Journal of Development and Administrative Studies. 2016;24(1-2):71-87.

14. Deo KK, Paudel YR, Khatri RB, Bhaskar RK, Paudel R, Mehata S, et al. Barriers to utilization of antenatal care services in Eastern Nepal. Frontiers in Public Health. 2015;3:197.

15. Simkhada B, Teijlingen ERv, Porter M, Simkhada P. Factors affecting the utilization of antenatal care in developing countries: systematic review of the literature. Journal of Advanced Nursing. 2008;61(3):244-60.

16. Joshi C, Torvaldsen S, Hodgson R, Hayen A. Factors associated with the use and quality of antenatal care in Nepal: a populationbased study using the demographic and health survey data. BMC Pregnancy and Childbirth. 2014;14(1):94.

17. Rai RK, Singh PK, Singh L. Utilization of maternal health care services among married adolescent women: insights from the Nigeria Demographic and Health Survey, 2008. Women's Health Issues. 2012;22(4):e407-e14.

18. Chompikul J, Isaranurug S. Factors related to the utilization of antenatal care services among pregnant women at health centers in Aceh Besar district, Nanggroe Aceh Darussalam province, Indonesia. J Publ Health Dent. 2008;6(2):99-108.

19. Kenthongkham K. Knowledge, attitude and antenatal care practices of women at Ad Distict, Huaphane Province, Laos. Health Service System Management. 2007;53:45-63.

20. Ye Y, Yoshida Y, Harun-Or-Rashid M, Sakamoto J, Sakamoto J. 
Factors affecting the utilization of antenatal care services among women in Kham district, Xiengkhouang province, Lao PDR. Nagoya J Med Sci. 2010;72(1-2):23-33.

21. Upreti SR, Baral S, Lamichhane P, Khanal MN, Tiwari S, Tandan M, Elsey H, Lievens T. Rapid assessment of the demand side financing schemes: Aama and 4 ANC programmes (the seventh rapid assessment). Ministry of Health and Population; Nepal health sector support programme and health research and social development forum, Kathmandu, Nepal, 2013.

22. Malla D, Giri K, Karki C, Chaudhary P. Achieving millennium development goals 4 and 5 in Nepal. BJOG: An International Journal of Obstetrics \& Gynaecology. 2011;118:60-8. 